\title{
Er brachte Farbe und Leben in die $\mathrm{SÄZ}$
}

\section{Bruno Kesseli}

Dr. med. et lic. phil., Chefredaktor

Es ist eine der Geschichten, von denen man wünscht, das Leben hätte sie nicht geschrieben. Eben hatte ich Badoux' unlängst erschienenes Buch nochmals durchgeblättert, weil ich eine Rezension dazu verfassen wollte. Hatte mich an den für die SÄZ entstandenen Comics und Cartoons erfreut, die unter dem Titel Krank geschrieben zu einem farbigen Bändchen zusammenge-

\section{«Lebensprühend» war denn auch das Adjektiv, das für die geplante Buch- besprechung gesetzt war.}

fasst worden waren. Da erreichte mich die Nachricht von Badoux' Tod. Aus heiterem Himmel, ohne Vorwarnung, hatte das Herz des 52-jährigen Künstlers aufgehört zu schlagen. Das Buch ist damit unversehens auch zu einem künstlerischen Vermächtnis geworden.

Die Erschütterung, die diese Mitteilung bei mir auslöste, war wohl auch deshalb so gross, weil ich Badoux bei unseren zwar nicht häufigen, aber sehr herzlichen und bereichernden Begegnungen als eine äusserst vitale Person erlebt habe. "Lebensprühend» war denn auch das Adjektiv, das für die geplante Buchbesprechung gesetzt war. Umso unfassbarer war es, dass Christophe, den ich wie viele stets mit seinem Künstlernamen Badoux angesprochen habe, nun plötzlich nicht mehr da sein sollte.

«Mitten im Leben sind wir vom Tod umfangen.» Dieser mittelalterliche Ausspruch, der heute vor allem mit dem Vergänglichkeitsbewusstsein der Barockzeit assoziiert wird, ging mir seither immer wieder durch den Kopf. Auch in einer Zeit, in der er nach Möglichkeit aus dem Gesichtsfeld verbannt wird, bleibt der Tod eine unkontrollierbare Grösse. Sie kann sich jederzeit machtvoll in Erinnerung rufen und scheinbar «erdbebensichere» Lebenskonstrukte gewissermassen mit einem Fingerschnippen zum Einsturz bringen.

Wie weit Badoux in seiner Lebendigkeit auch davon entfernt schien: Künstlerisch kannte er keine Berührungsängste mit dem Tod. In seinen Zeichnungen für die SÄZ liess er ihn in der allegorischen Form des «Sensenmanns» gerne auftreten. Wie er mir einmal verriet,

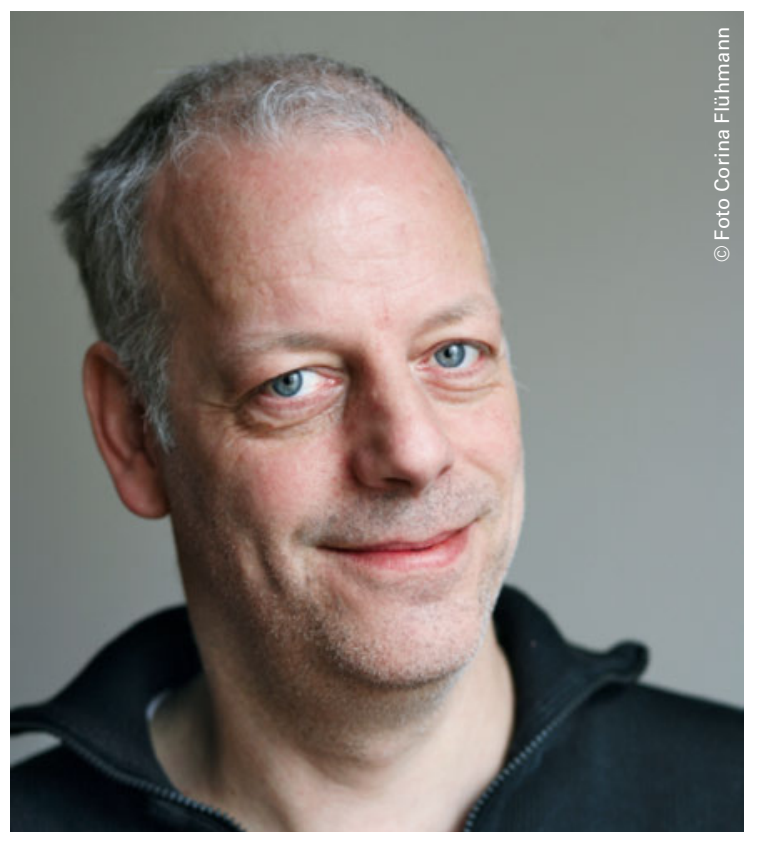

Christophe Badoux (1964-2016)

entwickelte er zunehmend Freude an dieser Figur, nachdem er sie zunächst - einer spontanen Idee folgend eher zufälligerweise eingeführt hatte. Doch bei Badoux war selbst der Tod erstaunlich lebendig. In seiner Kutte auf der Analysecouch liegend, gestand der Schnitter in einem Cartoon seinem Psychiater zwar niedergeschlagen, er habe Angst vor dem Leben. Aber wenn er sich in einem andern Comic mit einem Kollegen an der Bar ein «Grosses» genehmigte, konnte er auch tüchtig

\section{Doch bei Badoux war selbst der Tod erstaunlich} lebendig.

über die «elenden Warmduscher» von Ärzten herziehen. Statt wie in den guten alten Zeiten mit ihm um jede einzelne Seele zu ringen, verschrieben sie sich zusehends der Sterbehilfe, empörte er sich. «Wo bleibt da der Sportsgeist?», fragte er seinen Kumpel frustriert. «An ihren Früchten sollt ihr sie erkennen.» Dieser Satz gilt zweifellos auch für Badoux. Seine Zeichnungen sind farbenfroh, aber nicht marktschreierisch. Sie zeichnen sich durch eine klare Linienführung aus - nicht 
zufällig wird der von ihm repräsentierte Stil als «ligne claire» bezeichnet -, haben aber oft etwas Verspieltes. Ihr Humor kann intellektuell-feinsinnig sein, wirkt aber nicht selten auch kindlich oder gar derb. Von manchen Ärzten wurde er gelegentlich als kindisch empfunden, vor allem, wenn er die Psychiater auf die Schippe nahm, denen er ein "unglaubliches Witz-Potential» attestierte. Als Chefredaktor durfte man sich dann an

\section{Schalk, mitunter gepaart mit einer Dosis Provokationslust, blitzte im Gespräch oft in seinen Augen auf.}

entsprechenden, per Mail zugestellten Kommentaren erfreuen. "Nicht witzig», lautete ein solcher beispielsweise kurz und bündig. Anrede und Unterschrift hatte sich der Verfasser erspart.

Wenn man ihm solche Reaktionen zutrug, hatte man das Gefühl, dass sich Badoux diebisch darüber freute. Sie waren ihm Beweis dafür, dass er es geschafft hatte, das Fachpublikum der SÄZ aus der Reserve zu locken. Mangelnden Sinn für Humor hätte ihm sicher niemand vorgeworfen, der ihn näher kannte. Schalk, mitunter gepaart mit einer Dosis Provokationslust, blitzte im Gespräch oft in seinen Augen auf. Er verstand sich keineswegs als Medizin-Insider. Vor der ärztlichen Tätigkeit hatte er grossen Respekt, erstarrte vor den (ehemaligen) Halbgöttern in Weiss aber nicht in Ehrfurcht und wollte sich auch nicht mit ihnen anbiedern. «Ich hole Hochtrabendes gerne auf den Boden herunter. So werde ich versuchen, den Laienblick in diese Fachzeitschrift zu

\section{Auch bei der SÄZ hinterlässt dieser \\ «bunte Vogel» eine schmerzliche Lücke.}

bringen", sagt er im schönen Porträt, das Daniel Lüthi im Jahr 2014 für die SÄZ verfasst hat [1]. Diesen Anspruch hat er eingelöst, was ihm seitens der Leserinnen und Leser auch immer wieder Lob eintrug.

Eine weitere Anekdote illustriert trefflich die Spannweite, die Badoux abdeckte. Ein Kollege wollte mit mir bei einem Treffen die Qualität des SÄZ-Cartoons kritisch diskutieren. Anhand einer Reihe von Zeichnungen versuchte er zu begründen, warum die in der Rubrik zum Zug kommenden Künstlerinnen und Künstler «SÄZ-Niveau» hätten oder eben nicht. Badoux war als Einziger in beiden Kategorien vertreten - der Kollege hatte nicht realisiert, dass das "gute» und das «schlechte» Beispiel in einem Fall vom gleichen Künstler stammten. Angesichts von Badoux' unverwechselbarem Stil erstaunlich, aber wahr.

Ich habe bei der einen oder anderen Gelegenheit versucht, Badoux dafür zu sensibilisieren, wie Ärztinnen und Ärzte "ticken", sofern eine solche Pauschalisierung der sehr heterogenen Ärzteschaft überhaupt zulässig ist. Er war immer sehr offen und interessiert, zeigte sich bisweilen verblüfft darüber, was man in seine Zeichnungen hineininterpretieren konnte, wenn man sie durch die fachliche Brille betrachtete. Seiner klaren Linie blieb er aber stets treu, nicht nur stilistisch.

Wie schmerzlich der Verlust von Badoux für seine Angehörigen und Freunde, vor allem für seine Frau und seine Kinder ist, können wir Aussenstehenden nur erahnen. Aber auch bei der SÄZ hinterlässt dieser «bunte Vogel» eine tiefgehende Lücke. Dass er in seinen Werken präsent bleiben wird, mag denjenigen, die ihm nahe standen, zunächst als schwacher Trost erscheinen. Aber die Zeit wird dies ändern, da bin ich mir sicher.

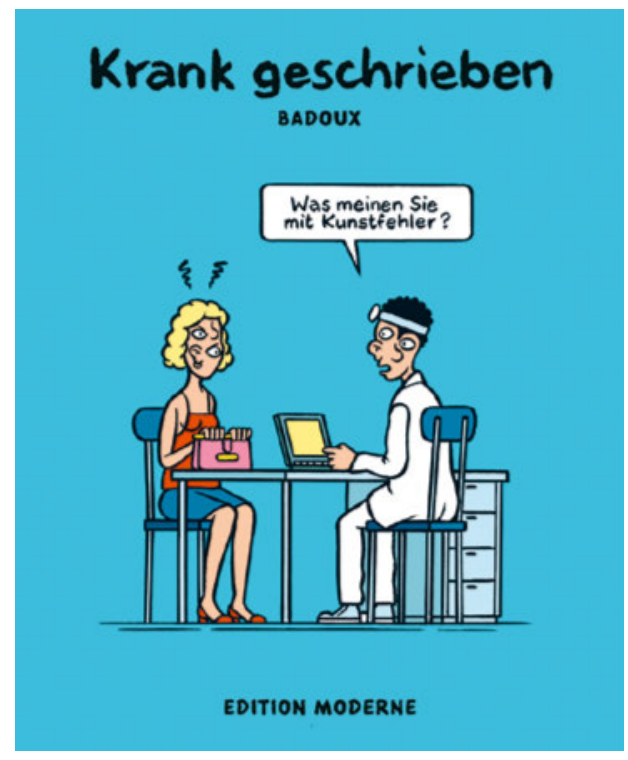

\section{BADOUX}

\section{Krank geschrieben}

Zürich: Edition Moderne; 2016.

16.00 CHF, 48 Seiten.

ISBN 978-3-03731-153-0

Das Buch kann auch bei EMH bezogen werden. 